\title{
Cuidado espiritual ao paciente terminal: uma abordagem a partir da bioética
}

\section{Spiritual care to the terminal patient: an approach starting from the bioethics}

\author{
Joseane de Souza Alves \\ Universidade do Vale do Rio dos Sinos (Unisinos), São Leopoldo, Rio Grande \\ do Sul, Brasil. \\ joseane.ars@gmail.com

\section{Lucilda Selli} \\ Universidade do Vale do Rio dos Sinos (Unisinos), São Leopoldo, Rio Grande \\ do Sul, Brasil. \\ lucilda@unisinos.br
}

Resumo: Artigo elaborado a partir de estudo qualitativo que levanta as características bioéticas no cuidado espiritual ao paciente terminal. Foi aplicado questionário e realizada entrevistada individual semi-estruturada com sete pastoralistas de hospitais da área metropolitana de Porto Alegre, escolhidos intencionalmente. Foi constatado que a formação em enfermagem não prepara o profissional para atender as necessidades espirituais do paciente terminal; mas, mesmo assim, esse tipo de cuidado se inclui entre suas tarefas. Frente a isso o estudo aponta a necessidade das funções das capelanias serem mais bem definidas e integradas às da enfermagem, para que o paciente terminal possa receber o cuidado espiritual adequado, sem sofrer interferências. A partir de parâmetros da bioética, a análise propõe uma integração entre o profissional de saúde e o espiritualista, no cuidado ao paciente. Como campo de reflexão isento de determinismos, a bioética revela-se instrumento capaz de orientar condutas, evidenciadas nas falas dos entrevistados. O esforço de captar as peculiaridades vivenciadas pelos pacientes nas situações concretas, traduz o espaço da bioética no campo da espiritualidade.

Palavras-chave: Bioética. Enfermagem. Espiritualidade. Paciente terminal.

\begin{abstract}
Article written from a qualitative study which points out the bioethical characteristics of spiritual care of terminal patients. A questionnaire and a semi-structured interview have been applied to seven pastorialists at hospitals in the metropolitan area of Porto Alegre, intentionally chosen. We concluded that nurses are not adequately prepared to fulfill spiritual needs of terminal patients but nevertheless this kind of service is included as part
\end{abstract}




\section{Revista Brasileira de Bioética}

of their tasks. This study, therefore points out the need of better defining chapel services and integrating them to nursing, in order to promoting suitable spiritual services to terminal patients, without further interferences. Following bioethical parameters, this analysis proposes integration between health professionals and spiritual care providers in dealing with patients care. As a field of reflection free from determinisms, bioethics ca be seen as a tool capable of conduct guiding - as suggested by the interviewed discourses. The effort to capture the peculiarities experienced by patients the concrete situations highlights the role of bioethics in the field of the spirituality.

Keywords: Bioethics. Nursing. Spirituality. Terminal patient.

Neste início de século, a dimensão espiritual da vida humana vem sendo valorizada na busca de aprofundar a relação entre saúde e religião. No contexto do presente trabalho, entende-se religião na sua essência de espiritualidade e não a partir de suas expressões concretas ao longo da história humana, que têm variado significativamente no correr do tempo. A espiritualidade é gestora da esperança, dos grandes sonhos, de um futuro transcendente do ser humano e do universo. Reafirma o futuro da vida, contra a violência da morte. Sem ela a ética tende a se transformar num código frio de preceitos, normas e dogmas e as várias morais em processos de controle social e de domesticação cultural.

A ética se associa à noção de espiritualidade, remetendo à esfera mais profunda da psique humana, àquele conjunto de visões, sonhos, utopias e valores que orientam e dão sentido às ações. A noção de espiritualidade agregada à ética pode ser também entendida como sabedoria, como o saber/fazer que instaura uma práxis que não pode ser resumida na razão fria, norteada apenas por princípios dogmáticos, sejam de cunho religioso ou laico. Seguindo essa definição de espiritualidade, um dos grandes desafios a ser enfrentado para a vivência de inter-relações pautadas por parâmetros éticos nas sociedades contemporâneas, advém da aceitação da dimensão espiritual como parte da totalidade humana. Inerente a isso, levanta-se também a questão do pluralismo religioso, reinante hoje, frente ao qual faz-se necessário fortalecer a vivência ecumênica, que deve ser marcada pelo diálogo, respeito e tolerância (1). 
Este artigo apresenta resultado de pesquisa qualitativa feita com pessoas que trabalham no campo da espiritualidade em diferentes instituições de saúde da região metropolitana de Porto Alegre, Estado do Rio Grande do Sul, Brasil. Discorre sobre a perspectiva dos entrevistados sobre a relação entre bioética e espiritualidade no cuidado ao paciente terminal, considerando a interface entre o tipo de cuidado prestado pelos profissionais de enfermagem e aquele próprio à assistência espiritual.

\section{Perfil pastoral dos agentes espirituais entrevistados}

A preparação específica de cada um dos sete entrevistados mostra que todos têm formação em pastoral e experiências práticas no atendimento espiritual ao paciente em fase terminal. A formação básica dos mesmos é a seguinte: dois pastores; duas enfermeiras; um frei católico; uma teóloga e educadora; e uma religiosa e auxiliar de enfermagem. A seguir, é apresentado um breve perfil de cada um deles.

O primeiro pastor evangélico é da Igreja Batista da Grande Porto Alegre, possui 13 anos de formação em teologia e especialização em capelania hospitalar no Rio de Janeiro, onde cursou um estágio em hospital evangélico, com pacientes terminais;

O frei católico é professor e assistente espiritual em Seminário do Rio Grande do Sul. Visita pacientes em hospitais há muito tempo e fez preparação em Pastoral de Saúde junto aos capelães em hospitais, nos quais hoje exerce o ministério da Pastoral da Saúde;

A primeira enfermeira exerce a função de supervisora em hospital de Porto Alegre, é generalista e inclui em seu serviço a supervisão da equipe de Serviço de Pastoral da Saúde. Atuou ao longo de nove anos em UTI e durante doze anos exerceu o serviço de assistente espiritual a pacientes moribundos. Tem formação em ética e bioética, fez curso de capelania hospitalar em Seminário no Rio de Janeiro e estágio em hospital do mesmo Estado;

A teóloga e educadora é formada há 15 anos em um Instituto Evangélico de Educação Religiosa do Rio de Janeiro. Fez curso de especialização em capelania hospitalar durante um ano, com estágio em hospital da mesma localidade. Trabalha em Porto Alegre como capelã há 5 anos; 
O segundo pastor é capelão da Igreja Luterana da Grande Porto Alegre. Trabalha na área de aconselhamento em instituição de ensino. Fez preparação específica de capelania durante o curso de teologia;

A religiosa e auxiliar de enfermagem exerce a função em hospital da Grande Porto Alegre. Tem 22 anos de experiência e vivência em ambiente hospitalar, atendendo pacientes no serviço de pastoral, dedica-se de forma específica a pacientes terminais. Tem curso de formação superior em teologia;

Finalmente, a segunda enfermeira tem experiência profissional de 24 anos. Neste período, assistiu e auxiliou muitos pacientes terminais por meio do Serviço de Pastoral da Saúde Hospitalar. Lê e participa de palestras e encontros que abordam o tema da Pastoral da Saúde e sua aplicabilidade prática.

\section{Características do cuidado espiritual ao paciente terminal}

A espiritualidade, juntamente com a religiosidade, são fontes importantes de apoio existencial, beneficiando a saúde integral do ser humano (2). Enquanto no imaginário social aumenta, cada vez mais, a rejeição à morte, contribuindo para que o ato de morrer seja ostensivamente classificado como fenômeno "não natural" as religiões têm perdido adeptos entre os que acreditavam na vida após a morte, isto é, na imortalidade da essência humana (3). O duplo impacto dessas representações sociais acaba por trazer danosas conseqüências ao paciente terminal, as quais concorrem para o aumento de sua angústia e desconforto nos momentos que precedem à morte (4).

Como outros fenômenos da vida social, o processo de morrer pode ser vivido de distintas formas, de acordo com os significados compartilhados por esta experiência. Tais significados sofrem variação segundo o momento histórico e o contexto sócio-cultural no qual ocorrem. Morrer não é apenas um fato biológico, mas um processo construído socialmente. As idéias e rituais acerca da morte constituem um dos aspectos do processo de socialização, que ocorre em todas as sociedades. Então, tanto o morrer como o adoecimento, e os cuidados em torno destes dois fenômenos, não se distinguem das outras dimensões do universo das relações sociais e, em cada momento histórico, há uma produção de práticas e de representações significativas (5). 
Atualmente, nas sociedades ocidentais, observa-se um processo acentuado e crescente de evitação da morte, a criação de um verdadeiro tabu em torno dela: o mundo que rodeia as pessoas não as ensina a morrer. Tudo é feito para esconder a morte, para incentivar que se viva sem pensar nela. O cotidiano é moldado a partir de um padrão caracterizado pela idéia de resolutividade, voltado para objetivos a serem alcançados e apoiado em valores associados à efetividade das práticas e comportamentos cotidianos. Tampouco esse mundo que esconde a inolvidável verdade da finitude humana, ensina a viver. A existência se resume a uma corrida desenfreada em busca da felicidade material, à qual, se acaba por perceber, mais cedo ou mais tarde, não ser suficiente para conferir sentido à existência (6).

Nesse contexto, pequenos gestos de afeto e atenção influenciam a percepção do paciente a respeito daquilo que está vivendo. O paciente precisa encontrar pessoas solidárias que o auxiliem no enfrentamento de seu mal físico, de suas angústias e de suas necessidades espirituais. Para responder a tais necessidades, é preciso que aqueles que se propõem prestar tais cuidados tenham claro que essas representações sobre a morte (ou a falta de representações sobre ela), acabam por constituir obstáculos para que o paciente possa encontrar serenidade nesse momento crítico. E essa consciência vai depender da avaliação que quem presta esse cuidado tem sobre a vida e sobre a responsabilidade que tem em relação aos pacientes, em suas diferentes necessidades (7).

Em diálogo com os pastoralistas, estes referem que, entre pacientes que não professam uma prática religiosa, é freqüente observar que quando se deparam com a morte encontram grande apoio na religião, sentindo-se confortados pelas orações e pelos sacramentos. Também é comum encontrar pacientes que professem uma religião ou tenham grande espiritualidade e vivem um intenso conflito de fé diante da possibilidade de morte. Nesses casos, os profissionais que acompanham o seu drama, devem ajudá-los a descobrir e a expressar o que vai dentro de suas almas. A espiritualidade pode surgir frente ao adoecimento, como um recurso interno que favorece a aceitação da doença, o empenho no restabelecimento, a aceitação de sentimentos dolorosos, o contato e o aproveitamento da ajuda das outras pessoas e até a própria reabilitação. 


\section{Revista Brasileira de Bioética}

Quanto a caracterização do cuidado espiritual ao paciente terminal, um dos sujeitos da pesquisa considera "desafiador, porém sublime". Da mesma forma, outro entrevistado classifica o trabalho como "muito delicado e ao mesmo tempo natural". Um terceiro, complementa dizendo que é um momento que exige maturidade e serenidade: "O cuidado espiritual ao paciente terminal requer maturidade, serenidade e entender reações e estágios frente à morte, pois o paciente nesta fase deseja receber atenção e tratamento personalizado". Também foi relatado que o momento de morrer, assim como os que o precedem, "é um estágio particular e de muita importância para o paciente, exigindo habilidade e sensibilidade". Outro entrevistado enfatiza que o cuidado espiritual é um momento de fé, conforto, esperança e carinho, partilhado com o paciente: "Creio que este atendimento traz um referencial de fé, conforto, esperança e é uma manifestação de presença, carinho e cuidado relevante neste momento".

Entre as necessidades que se tornam evidentes no momento de terminalidade, destacam-se: o respeito pela autonomia da pessoa, que não significa abandoná-la à sua própria sorte; saber a verdade sobre sua condição de saúde e participar no processo de tomada de decisão; não deixá-la se sentir abandonada; ter sua dor e sofrimento cuidados; e não ser tratada como mero objeto. $O$ fator humano é indispensável, passando pela comunicação que ouve, acolhe e respeita o outro como pessoa; nas suas verdades, nos seus clamores, nos seus valores (8).

Considerando as recomendações dos tratados de direitos humanos como diretrizes para os padrões éticos que devem permear as relações entre as diversas sociedades e as inter-relações entre indivíduos que nelas vivem, a dimensão espiritual do ser humano, que é parte de seu arcabouço cultural, também precisa ser reconhecida, respeitada e respondida. Na área da saúde as distintas manifestações de crença na noção de transcendência devem ter espaço, da mesma forma que o reconhecimento do indivíduo como ser integral deve caracterizar as relações interpessoais e intergrupais no terceiro milênio, quando (se espera) cidadania e justiça passem a ser a tônica do novo paradigma para as relações sociais (9).

Esta concepção hodierna, que fundamenta a noção de humanidade, prescreve o respeito à dignidade do ser humano, à vida física, 
à integridade corpórea e à saúde, já não em nome de um vitalismo biológico, mas em relação à essência da pessoa, que se manifesta na totalidade de seu ser. Se o valor essencial é a dignidade da pessoa humana, para todos que crêem que pessoa é constituída por uma corporeidade animada por uma espiritualidade, o reconhecimento da sua humanidade passa pela aceitação dessa espiritualidade (10).

Nesse sentido, faz-se necessário salientar o papel da bioética, que aplica a reflexão ética nas ações concretas que envolvem o comportamento cotidiano e que propugna a aceitação tolerante ao outro e às diferenças, expressas e classificadas como pluralidade. A bioética, cumprindo seu papel de ponte para o futuro, pode promover a interface entre ciência e religião, que esconde a secular polêmica entre as "verdades" de ateus e religiosos. Exortando à reflexão e ao diálogo também àqueles que professam diferentes seitas e religiões, a disciplina pode contribuir para estabelecer padrões de convivência éticos, pacíficos e harmônicos.

Um dos entrevistados refere ao reconhecimento dessa necessidade por meio do cuidado espiritual. Classifica esse cuidado como sendo um momento benéfico para o paciente e gratificante para o pastoralista:

\begin{abstract}
"Posso dizer o quanto é benéfico ser presença junto ao paciente terminal, sem nos preocuparmos tanto com as palavras, o que dizer, mas ser presença que transmita conforto, segurança, compreensão da situação. É muito gratificante sermos instrumentos mediadores para o encontro definitivo com Deus".
\end{abstract}

Assim, a análise dessa questão mostra a importância de encampar o cuidado espiritual como maneira de responder às necessidades do paciente que professa uma crença ou vivencia a dimensão da espiritualidade. Aponta para o fato de que só é possível uma atenção integral ao paciente terminal que prescinde desse tipo de atenção, assim como o respeito efetivo à sua dignidade humana, quando se considerar a importância dessa dimensão. As entrevistas mostraram que, nos caso em que a espiritualidade se revela essencial ao próprio paciente, é possível constatar que tal forma de cuidado promove seu bem estar, 


\section{Revista Brasileira de Bioética}

configurando-se em possibilidade de alcançar maturidade e serenidade nesses momentos, bem como receber carinho e conforto.

A integração entre bioética e espiritualidade tem grande importância para o paciente terminal. Fica explícito, portanto, que ao apontar o benefício proporcionado por este tipo de cuidado e o conflito que pode decorrer de sua supressão, a bioética estará contribuindo não apenas para a incorporação da dimensão espiritual na concepção de ser humano, mas também para ressignificação dessa dimensão como necessidade cultural e, assim, como elemento inerente à própria dignidade humana.

\section{Preparo da enfermagem para o cuidado espiritual ao paciente ter- minal}

Por intermédio da vivência da espiritualidade, experimentam-se pessoalmente os misteriosos caminhos do eu profundo, suas contradições e mecanismos internos, suas formas simbólicas de expressão, sua capacidade de mobilizar energias intensas e de encontrar significados para as situações de crise. Observar esse processo traz à luz instrumentos para compreender os estranhos caminhos da alma dos pacientes, bem como os sutis significados de seus gestos, que passam a transparecer em seu olhar, expressão e fala. A espiritualidade capacita o profissional para lidar com as emoções intensas e os questionamentos angustiados dos pacientes e seus familiares em crise existencial, evitando que se assuma a atitude usual de fuga destas situações ou de criação de mecanismos de bloqueio da sensibilidade para poder preservar sua própria estabilidade emocional (11).

A importância de os profissionais estarem minimamente preparados para encarar esse tipo de situação decorre do fato que, atualmente, não se está acostumado a conviver com alguém que está morrendo. Antigamente não era assim. Agora o paciente fica no asilo ou hospital e não morre mais em casa $(12 ; 13)$. Se a família e amigos não têm mais contato pessoal com o paciente, comprometendo o cuidado espiritual, os profissionais de saúde também se sentem despreparados para dar-lhe assistência integral (14).

Em nossa sociedade, aprender a lidar com as perdas no contexto de uma doença crônica é um desafio que poucos se propõem a dis- 
cutir, e muito menos a enfrentar, sejam profissionais ou não. Controle dos sofrimentos físico, emocional, espiritual e social são aspectos essenciais que precisam orientar o cuidado e pode e deve ser oferecido aos indivíduos com doença terminal, desde o diagnóstico até o momento da morte, assim como aos familiares, durante o curso da doença e em programas de enlutamento (15). Ajudar indivíduos com doenças terminais e seus familiares, amparando-os em um dos momentos mais cruciais de suas vidas, é uma atividade ou um modelo de atenção à saúde que pressupõe a integralidade da assistência.

Quanto ao preparo dos profissionais de enfermagem, como equipe multicategorial, para cuidar das necessidades espirituais dos pacientes terminais, todos os entrevistados referem que os enfermeiros, em geral, não estão preparados para auxiliar o paciente em suas necessidades espirituais, o que fica evidenciado na fala a seguir:

"Diria que alguns sim e muitos não. Trabalhar com momentos tão dolorosos da vida humana e estar preparado para cuidar das necessidades espirituais dos pacientes terminais implica num processo pessoal de autoconhecimento, amadurecimento pessoal, um contato rico e produtivo com as próprias dores e conflitos, uma experiência de fé significativa. Mais que uma formação acadêmica, uma vivência pessoal significativa. O ser humano utiliza muitos mecanismos de defesa para fugir daquilo que o assusta e faz sofrer. Para alguns profissionais, a indiferença pela vida humana, às vezes, acaba sendo um modo de não entrar em contato com suas próprias dores e medo da morte. É relevante que o profissional desta área tenha um acompanhamento de maneira à 'estar se dando conta' de como as situações que lida afetam sua própria existência. Creio que alguns profissionais, em função de sua formação e, principalmente, de suas vivências, estão preparados, muitos não".

Um dos entrevistados fala que a causa dos enfermeiros não estarem preparados para prestar esse tipo de cuidado, decorre da falta de formação dos profissionais, que é marcada por um padrão de distanciamento em relação ao paciente, o qual causa ansiedade frente à situação terminal e, até mesmo, indiferença. Talvez falte a esses pro- 


\section{Revista Brasileira de Bioética}

fissionais confiança na sua capacidade de sentir empatia, solidariedade, atenção, presença e consideração pelo outro (6). Outro entrevistado complementa dizendo que falta também uma formação específica e base teológica pastoral. O mesmo sujeito diz que ainda persiste a idéia entre os profissionais, assim como em toda a sociedade, de que a doença é provação imputada por Deus ou castigo dele advindo:

"O carinho, a dedicação, a doação, fazem parte do cuidado espiritual, porém falta toda uma formação de base teológica pastoral para a equipe, de modo geral para o enfrentamento e elaboração das reações pessoais e de equipe frente ao paciente terminal. Persiste forte ainda a concepção de prova e castigo".

Um dos entrevistados relata que faltam cursos preparatórios aos profissionais para capacitá-los no acompanhamento das necessidades espirituais de pacientes terminais. Já outro diz que não considera que a falta desse tipo de cuidado se deva ao despreparo dos enfermeiros, mas sim ao ambiente de pressão e sofrimento, que tende a tornar esses profissionais "insensíveis, calejados": "Há carência neste campo, há pouco diálogo e muito remédio curativo".

Cada vez que o profissional de enfermagem se depara com a morte de um paciente, aumenta sua inquietação relativa à inexistência de programas e diretrizes que facilitem o enfrentamento do processo de morte e de morrer. Tem-se a atenção chamada para a forma como a maioria desses profissionais se comporta, parecendo, por vezes, banalizar um processo que, de forma alguma, pode ser considerado simples. Tal fato leva a conclusões sobre as justificativas para esses atos, inseridas, quem sabe, na estrutura da psique, que não admite a idéia da própria finitude. Então, desse pressuposto se pode inferir que a busca pela eternidade ou imortalidade, reflete o medo de morrer, que, até certo ponto, pode ser considerado natural para os seres humanos. Diferente dos outros animais, estes têm consciência da própria finitude e se interrogam sobre seu significado. Porém, agir como se alcançar a imortalidade fosse possível, deve ser atribuído também à forma como as representações sociais têm se transformado sob o cunho de uma visão estritamente material e física do ser humano, o 
que pode estar contribuindo para gerar preconceito crescente frente ao processo do morrer e na dificuldade de prover cuidado também nessa situação (6).

No tocante a isso, um entrevistado ressalta que a preocupação da enfermagem se restringe à parte técnica, deixando de lado os aspectos que envolvem outras necessidades do paciente:

"Penso que na grande maioria, os profissionais de enfermagem não estão preparados para cuidar das necessidades espirituais dos pacientes terminais. A preocupação está mais na parte técnica. Vejo a necessidade de incluir cuidados espirituais nos cursos acadêmicos".

Na transformação do ritual das sociedades frente à morte, os profissionais da saúde passaram a estar na linha de frente. É ao hospital que as pessoas confiam os seus moribundos. Neste contexto, começa a expressão da aflição dos profissionais da saúde, diante do sofrimento dos pacientes e das respectivas famílias, e também se manifesta a justa exigência de alguns quanto ao recebimento de uma formação específica para fazer frente a essa demanda.

Os enfermeiros são preparados no âmbito da fisiopatologia e dos procedimentos técnicos utilizados na atenção a pacientes graves, negligenciando, por conta dessa formação, os aspectos emocionais e psicológicos necessários ao atendimento de pessoas em situação de morte. Mesmo que o elemento religioso esteja presente na forma como muitos pacientes elaboram suas crises, os profissionais de enfermagem não têm preparo para discutir como lidar com essa religiosidade e lançam mão de suas convicções religiosas pessoais de forma acrítica e, por vezes, atabalhoada (14). Para responder a essa dimensão que extrapola o biopsicosocial é preciso aceitar a necessidade de transcendência inerente à pessoa humana, é necessário englobar a metafísica e refletir sobre ela, permitindo que a dimensão da espiritualidade manifeste-se nas ações cotidianas (16).

Mas, se a percepção do profissional sobre o paciente terminal é fragmentada a ponto de suas emoções serem, muitas vezes, desconsideradas como objeto do cuidado profissional, mesmo sendo estas emoções consideradas concernentes ao âmbito de atuação da ciência, 


\section{Revista Brasileira de Bioética}

o que não se pode dizer a respeito do cuidado à dimensão espiritual desse paciente, proposição que não tem sequer o mesmo respaldo científico? A ausência de qualquer formação neste sentido faz com que a participação dos enfermeiros no morrer dos pacientes os afete direta e profundamente, produzindo os mais diversos sentimentos. A sensação de impotência surge como decorrência da educação mecanicista recebida. A tentativa frustrada de manutenção da vida, por meio da utilização de recursos tecnológicos, acaba provocando estresse, em razão da responsabilidade assumida perante a família do paciente, que, nesse momento, representa a expectativa de toda sociedade (6).

Um entrevistado afirma que é possível aos enfermeiros também participar do cuidado espiritual do paciente. Mas, para isso, os profissionais precisam ter vocação, dedicação, ensino e treinamento. Outro entrevistado diz que, além de uma formação acadêmica que favoreça também um preparo teológico espiritual, é necessária uma vivência pessoal significativa, isto é, experiência de vida.

Num tempo histórico de fascínio pela tecnociência e suas descobertas que podem tornar o ser humano um mero detalhe ou objeto, é necessário superar esta "condição" mediante a valorização do ser humano em sua dignidade plena. Para isso, é preciso humanizar, no sentido literal e irrestrito do termo, aceitando, inclusive, a espiritualidade como parte inerente à cognição humana, relacionada à dimensão cultural. Para que se possa ser protagonista de ações humanizantes, cultivando o diálogo personalizador em vários âmbitos, principalmente nas situações de sofrimento e final de vida, é imprescindível que profissionais e instituições consigam prover cuidados também nessa dimensão àqueles que deles necessitam. Só assim é possível humanizar, de fato, a atenção e garantir dignidade diante do sofrimento humano (16).

É neste cenário que surge a necessidade de um resgate dos valores subjetivos, que foram diminuindo com os avanços da ciência. Para isso, é preciso o desenvolvimento de um novo olhar, de uma nova forma de atuar frente a essa realidade, consubstanciada em padrões éticos mais abrangentes. Não se trata de deixar de lado as inovações científicas e tecnológicas, mas sim de agregar valores humanos às relações que ocorrem nas instituições de saúde, buscando uma articu- 
lação baseada nos princípios éticos, que reconhecem a totalidade do ser humano, por meio de ações que respeitem e valorizem os diversos aspectos das pessoas envolvidas (17).

A especificidade da formação interfere na conscientização e reflexão da enfermagem com relação à importância da espiritualidade no cuidado ao paciente terminal que demanda essa forma de atenção, sendo obstáculo para que se possa definir com clareza a melhor maneira dos profissionais de saúde contribuirem para o bem estar desses pacientes, de forma mais abrangente. Para a enfermagem integrar ao rol de suas práticas diárias de cuidado ao paciente terminal os princípios da prática bioética e os pressupostos da dimensão da espiritualidade, precisa habituar-se a ver o paciente na sua totalidade. Nesse sentido, ao apontar o conflito que vivem os profissionais, que se reflete na dificuldade em prestar esse tipo de cuidado ao paciente, a bioética está contribuindo para construir uma reflexão voltada ao reconhecimento integral da pessoa humana.

\section{Inclusão do cuidado espiritual ao paciente terminal no trabalho da enfermagem}

Excetuando-se as situações nas quais a sobrecarga de trabalho pode chegar a comprometer a atuação profissional, o enfermeiro busca o que entende ser bom para o paciente e, com base nos fundamentos de seu saber técnico, promove seu bem estar e protege seus interesses. Como decorrência de seu contato contínuo com o paciente, a enfermagem tem uma convivência mais simples com a morte, pois faz parte do seu dia-a-dia e não representa uma derrota profissional. Portanto, a enfermagem pode dar assistência integral aos pacientes, mas, para isso, é preciso que os profissionais que se dispõem a propiciar tal confirto desvendem maneiras de, na sua profissão, oferecer aos pacientes terminais cuidados que venham ao encontro das necessidades dos mesmos (14).

As falas dos entrevistados evidenciam que consideram que a boa prática profissional nessa área precisa aliar ao cuidado com o corpo, a atenção às dimensões social, psíquica e, principalmente, espiritual (18). Porém, ao fazer isso, não se pode desconsiderar a manifestação da vontade, desejos, sentimentos, crenças, enfim, as opções de cada 


\section{Revista Brasileira de Bioética}

um (19). A respeito, um dos entrevistados relata que "a fé cuida da pessoa toda, e os remédios somente do corpo". Outro complementa dizendo que a fé proporciona mais serenidade e felicidade ao paciente: "O paciente se sentiria mais sereno e feliz se ouvisse da equipe de enfermagem que a fé também cura".

Com relação à inclusão do cuidado espiritual ao paciente terminal no trabalho de enfermagem, somente um dos entrevistados pensa não ser um tipo de cuidado a ser dispensado pelos enfermeiros, pois exige pessoas preparadas para tal. Para ele, o enfermeiro deve somente auxiliar cuidadores especialmente habilitados para isso, por ser uma tarefa séria e cuidadosa. Os outros referem que o cuidado espiritual deve estar incluído no trabalho de enfermagem. Um dos entrevistados justifica esta possibilidade, dizendo que o contato constante que o enfermeiro tem com os pacientes, favorece ao mesmo perceber essa necessidade e auxiliá-lo: "O cuidado espiritual ao paciente terminal deveria estar incluído no trabalho da enfermagem pelo contato constante com o paciente, tornando muito mais fácil cuidar deste assunto com os pacientes".

Diante de tal ponto de vista, seis entrevistados defendem que deveria haver treinamentos para os profissionais de enfermagem, preparando-os e capacitando-os no encaminhamento de questões desta ordem no próprio local de trabalho. Segundo eles, esses treinamentos deveriam estar incluídos no currículo de maneira teórica e prática. Para esses entrevistados, o vínculo criado entre enfermeiro e paciente facilita o cuidado espiritual, porque amplia a confiança e a comunicação entre eles.

Nos relatos dos entrevistados, constata-se que consideram que há a possibilidade da enfermagem prestar um cuidado que abranja a espiritualidade dos seus pacientes, pois agregá-lo ao cotidiano do serviço seria uma questão de perceber a pessoa na sua totalidade. A enfermagem teria que aproveitar esse contato direto, pessoal e contínuo com os pacientes, para ajudar os doentes terminais a ter uma morte tranqüila. Entendem, no entanto, que para isso os profissionais de enfermagem precisam receber treinamento, seja no decorrer do curso ou até mesmo no local de trabalho, por pessoas habilitadas e experientes na área. Este cuidado supõe respeito e experiência de vida da pessoa, aí incluída a dimensão da espiritualidade. 
A tendência crescente da enfermagem em ver o indivíduo de uma maneira holística, gera questionamentos sobre o cuidado nessa dimensão. Corpo, mente e espírito, devem ser percebidos mais do que como produto de uma soma de partes, mas como dimensões que interagem. Assim, tratando uma delas, as demais serão afetadas. Embora se admita que esta interdependência exista, as intervenções de enfermagem são escolhidas e implementadas de maneira fragmentada, segundo as alterações associadas a cada dimensão (20). É necessária, então, uma preparação acadêmica que reforce o respeito pelo paciente como pessoa assim como por sua crença.

Se o cuidado ao paciente deve ser altamente técnico e científico, também é importante a capacidade de sentar-se junto à cabeceira do paciente, ter tempo e paciência para ouvir suas queixas, sua insegurança, sua história de vida; isso também faz parte do processo de cuidado. Diante da situação difícil de assistir um paciente em fase terminal, a espiritualidade revela-se fonte de paz e esperança, tanto para os profissionais como para os pacientes. Nessas condições, cabe à bioética propugnar para que se reconheça a importância desse tipo de atenção capaz de prover o cuidado integral, tão importante e necessário tanto para a saúde e a vida dos pacientes, quanto em seus momentos finais.

Então, falar em bioética nessas circunstâncias é falar em medidas que englobam a pessoa de uma forma integral: biológica (física), emocional e mental (psicológica), social e espiritual. Trabalhá-las a partir da reflexão bioética implica em sensibilização para entender e responder a essas dimensões; só é possível cuidar integralmente do outro, se todas essas dimensões são contempladas. Pode-se começar simplesmente com o olhar: olhando verdadeiramente para o outro. Olhar para o outro pressupõe calar, ouvir verdadeiramente o que o outro tem para dizer, fitar seu olhar, esquecer de si e perceber o outro em suas necessidades físicas e emocionais. Mas, para ser capaz disso, há que se ser capaz também de olhar para si mesmo, ouvir verdadeiramente as próprias necessidades, ponderar sobre o que faz bem e o que faz mal, para perceber nessas necessidades físicas e emocionais o espelho através do qual se pode entender, captar e responder ao olhar do outro (21).

Tanto quando se põem em prática os princípios que orientam o 


\section{Revista Brasileira de Bioética}

diálogo bioético, quanto quando se prestam os cuidados relativos à espiritualidade, se parte de uma atitude em comum: permanecer sensível e aberto para falar aquilo que se entende ser o melhor para o paciente. É nessa forma de relação que é possível encontrar o jeito certo e descobrir a hora adequada de falar, como falar e o que falar.

\section{Integração enfermagem e capelania}

A reflexão bioética mostra que a espiritualidade está ligada a valores socioculturais, à solidariedade, à compaixão, à capacidade de colocar-se no lugar do outro e se preocupar com seu sofrimento e, se possível, amenizá-lo. Está associada às qualidades do espírito humano: amor, tolerância e capacidade de perdoar, que trazem felicidade para a própria pessoa e para os outros (22). A ampliação do conceito de saúde, que tem se tornado mais complexo, também permite incorporar a noção de espiritualidade, promovendo uma atenção mais acurada a essa dimensão (23).

Se a dimensão espiritual é inerente ao indivíduo, torna-se importante para os enfermeiros avaliá-la e nela intervir quando necessário. Entretanto, essa dimensão deve ser diferenciada do aspecto religioso e do comportamento psicossocial. Para diferenciar esse aspecto, é importante que haja estudos que definam a espiritualidade por meio de reflexões que levem em conta sua especificidade (24). A integração entre ciência e espiritualidade tem grande importância no enfrentamento dos problemas de saúde não só para os indivíduos, como também para a coletividade (11). Nesse sentido, estudos em bioética, especialmente os voltados à bioética clínica, já vêm trabalhando propostas para a integração entre os profissionais que atendem o paciente, buscando entender o homem na sua essência, em sua natureza, em sua verdade, em sua totalidade e em sua unidade (25).

Para entender a espiritualidade como um aspecto importante no processo terapêutico, e essencial para o bem-estar, é necessário considerar a pessoa como ser holístico. O profissional de saúde pode ajudar o paciente, ouvindo, estando atento às suas emoções e aos seus sentimentos. Muitas vezes, isso é mais importante que qualquer

terapêutica. É necessária uma preparação acadêmica que reforce o respeito pela pessoa e por sua crença. Para atender às necessidades 
espirituais do paciente, não há regra nem formula únicas. Quem tem contato diário com os pacientes e com seu sofrimento, sabe que cada pessoa sente de forma diferente, a partir de vivências próprias, objetivo de vida próprio, e espiritualidade própria (26). As reações de estresse do paciente variam de indivíduo a indivíduo, tornando-se assim evidente a necessidade de acolhimento e valorização da pessoa neste momento (27).

O trabalho conjunto entre a enfermagem e a capelania no cuidado ao paciente terminal é uma tarefa difícil. É preciso haver interesse comum pelo paciente. Os dois setores têm que falar a mesma linguagem e deve haver entre ambos diálogo e respeito. É importante a definir as tarefas de cada um e colaboras para a integração entre os setores. Constatou-se, também, a importância da continuidade ao cuidado espiritual prestada pelos agentes espirituais e o fornecimento de informações do paciente, num trabalho integrado entre enfermagem e capelania, com o repasse de aspectos significativos colhidos pela enfermagem, para o serviço pastoral.

Quanto à organização e desenvolvimento de um trabalho integrado entre a capelania e a enfermagem, no sentido de oferecer o cuidado espiritual ao paciente terminal, um dos entrevistados afirma que esse tipo de trabalho é difícil hoje, em nossos hospitais, e que precisa haver interesse comum pelo paciente, tanto por parte da enfermagem como da capelania. Outro entrevistado comenta que os dois setores têm que falar a mesma linguagem. As reuniões, complementa um dos entrevistados, precisam ser conjuntas, com as mesmas informações sobre o paciente, e devem seguir a mesma conduta "...através de reuniões conjuntas onde ambas as partes tenham as mesmas informações sobre o paciente e tenham conduta igual em relação ao mesmo e também à sua família".

Outro entrevistado também considera importante o diálogo entre profissionais de enfermagem e a capelania, afirmando que a necessidade do trabalho integrado tem que ser assumida. Segundo ele, o enfermeiro pode fornecer os dados gerais do paciente e a capelania entra com o cuidado espiritual, tanto para o paciente como para os profissionais de enfermagem. Continuando, um dos entrevistados ressalta que a capelania pode atender também os profissionais. Outro sujeito da pesquisa coloca que os assistentes espirituais podem ofe- 


\section{Revista Brasileira de Bioética}

recer cursos, seminários, acompanhar e supervisionar a enfermagem no cuidado espiritual.

Um entrevistado considera que os enfermeiros devem receber habilitação para tal tarefa. Outro, coloca como importante os treinamentos, congressos, seminários e jornadas com temas específicos. Um terceiro, fala ainda de palestras, cursos e troca de experiências. Por fim, há um que lembra que não é suficiente uma formação específica, mas que deve haver integração entre as duas partes, conscientização, diálogo e respeito: "Para um trabalho integrado, se faz necessário uma organização entre equipe de enfermagem e capelania, para que nenhum paciente fique privado do direito à assistência espiritual".

Portanto, as falas indicam que os entrevistados consideram que é importante que estejam bem definidas as tarefas da enfermagem e da capelania, havendo colaboração, diálogo e integração entre os setores. No momento em que as funções da capelania e enfermagem estão definidas, o paciente poderá receber um cuidado adequado e contínuo, que abranja os princípios da bioética e da espiritualidade. A equipe de enfermagem precisa repassar as informações biopsicosocioespirituais do paciente aos assistentes espirituais, facilitando seu trabalho, preservando sempre a privacidade do enfermo.

Como foi relatado pelos entrevistados, uma maneira da enfermagem e capelania realizarem esse trabalho integrado seria por meio da intensificação do diálogo e respeito mútuo. Entende-se que reuniões para troca de informações e para traçar linhas de ação são muito importantes, bem como os treinamentos para os enfermeiros. Esses treinamentos podem ser dados pela própria capelania. A enfermagem deve buscar mais condições para incluir em seu cuidado ao paciente terminal os aspectos bioéticos e espirituais, tanto por meio de seminários e cursos, como de leituras complementares.

A integração entre ciência e espiritualidade tem grande importância no enfrentamento dos problemas de saúde não só para os indivíduos, como também para a coletividade (11). A bioética tem uma proposta de integração entre os profissionais que atendem o paciente e busca entender o homem na sua essência, em sua natureza, em sua verdade, em sua totalidade e em sua unidade (18). 


\section{Considerações finais}

O cuidado espiritual ao paciente terminal caracteriza um desafio. Supõe formação específica, maturidade, habilidade, serenidade e sensibilidade às reais necessidades do outro. Traduz um momento importante para o paciente e gratificante para o assistente espiritual. Os profissionais de saúde e, especialmente os enfermeiros, não estão preparados para prestar esse tipo de cuidado ao paciente terminal. Este cuidado implica um processo pessoal de autoconhecimento e amadurecimento, além de prescindir, em grande parte, de uma experiência de fé significativa. É preciso saber entrar em contato com as próprias dores e com o medo da morte.

A dimensão espiritual precisa ser reconhecida como um elemento importante (senão fundamental) da cognição humana e parte essencial da perspectiva cultural dos seres humanos. Em decorrência disso, tende $\mathrm{a}$, paulatinamente, tomar vulto como elemento constituinte de um novo paradigma social, calcado na ética e no respeito às expressões humanas em sua totalidade. Por meio da reflexão, como a que se propõe a bioética, cada vez mais se reconhece o papel e a importância da espiritualidade no processo de recuperação da saúde e enfrentamento da doença. Assim, atuando de maneira conjunta, bioética e espiritualidade beneficiam a saúde integral do homem e capacitam o profissional de saúde a lidar com o paciente terminal.

Os parâmetros da reflexão bioética se fazem presentes nos relatos dos entrevistados, quando apontam a necessidade de responsabilidade, a troca de conhecimento, o pluralismo, a superação de posturas sectárias e a preservação do caráter plural da discussão. Incorporar a dimensão da espiritualidade nos cuidados inerentes à prática cotidiana da saúde, especialmente no que tange aos dispensados pela enfermagem, implica em considerar a bioética como mais um aporte para reflexão sobre as práticas e a implementação do saber/fazer da enfermagem, que supõem desenvolver e aprofundar a capacidade de captar relações de significado entre as diferentes instâncias de saber. 


\section{Revista Brasileira de Bioética}

\section{Referências}

1. Pessini L. Saúde, religião e espiritualidade. Disponível em www.sbggrj.org. br/artigos/saude.htm.

2. Campos S. Medicina avançada - núcleo interdisciplinar de bioética. Disponível em www.drashirleydecampos.com.br/noticias.php.

3. Lichtenfels H. Saúde e espiritualidade: sentido de vida no envelhecimento. In: Noé SV (org.). Espiritualidade e saúde - da cura d'almas ao cuidado integral, São Leopoldo: Sinodal; 2004.

4. Küber-Ross E. Sobre a morte e o morrer. São Paulo: Martins Fontes; 2000.

5. Menezes RA. Etnografia de um hospital de cuidados paliativos. Tanatologia e Subjetividades, Revista do Núcleo de Estudos e Pesquisa em Tanatologia e Subjetividades da Universidade Federal do Rio de Janeiro. Disponível em www.ess.ufrj.br/download/revista_mar06.doc.

6. Nunes Fernandes ME; Carvalho Fernandes AF; Pereira de Albuquerque AL \& Mota, MLS. A morte em unidade de terapia intensiva: percepção do enfermeiro. Rene, Revista da Rede de Enfermagem do Nordeste, Fortaleza, 2006;7(1). Disponível em www.portalbvsenf.eerp.usp.br/scielo.php.

7. Cavalcanti EV. Aconselhamento a pacientes terminais. São Paulo: Presbiteriana; 1983.

08. Pessini L. Nem abreviar, muito menos prolongar a vida, mas humanizar e cuidar. Disponível em www.amaivos.uol.com.br/templates/amaivos.

9. AFECES - Gestão humanizada. Disponível em www.afecesconsultoria. com/pace.htm.

10. Batistioli J. Bioética e religião. São Paulo: Associação de Educação Católica de São Paulo. Disponível em www.aec-sp.org.br/downloads/aec/jbatistioli.pdf. 11. Vasconcelos EM. A espiritualidade no trabalho em saúde. São Paulo: Hucitec; 2006.

12. Áries P. História da morte no ocidente. Rio de Janeiro: Ediouro, 2003.

13. Rodrigues JC. Tabu da morte. Rio de Janeiro, Fiocruz, 2006.

14. Calannam N. Gestos finais: como compreender as mensagens e a condição especial das pessoas que estão morrendo. São Paulo: Nobel; 1994.

15. Ferreira da Silva RC \& Hortale VA. Cuidados paliativos oncológicos: elementos para o debate de diretrizes nesta área. Cadernos de Saúde Pública. 2006;22(10). Disponível em www.scielo.br/scielo.php.

16. Ramos DLP. Fundamentos e princípios da bioética. Disponível em www. hottopos.com/notand9/dalton.htm.

17. Leite TA \& Strong MI. A influência da visão holística no processo de humanização hospitalar. O mundo da saúde 2006;30(2):207.

18. Pessini L. Morrer com dignidade, como ajudar o paciente terminal. Aparecida do Norte: Santuário; 1990.

19. Zoboli EL \& Sartório NA. Bioética e enfermagem: uma interface no cuidado. O mundo da saúde 2006;30(3):384-85. 
20. Marques LF. A saúde e o bem-estar espiritual em adultos Porto-Alegrenses. Psicologia, ciências e profissão, Conselho Regional de Psicologia, Porto Alegre, 2006. Disponível em revista@pol.org.br.

21. Goldin JR. Bioética e espiritualidade. Disponível em www.ufrgs.br/bioetica/espirit.htm.

22. Fortaleza. Secretaria Municipal da Fazenda. Cláudio Roberto. Disponível em http://infobase.2it.com.br.

23. Goldin JR. Op. cit.

24. Benko MA \& Silva MJ. Pensando a espiritualidade no ensino de graduação. Rev Latino-Americana de Enfermagem, 2006. Disponível em www.rlaeeerp.usp.br.

25. Saúde e espiritualidade, uma nova visão do ser humano. Clinionco, ago/ set 2005; ano II(8). Disponível em www.clinionco.com.br/informativo/capa

26. Lourenço I. A espiritualidade no processo terapêutico - Realidade e importância. Disponível em www.quarteto-pt/o livro/defaut.asp.

27. Glanzner CH, Zini LW, Lautert L. Programa de atendimento da enfermagem na admissão e alta hospitalar. Rev Gaúcha Enfermagem 2006;27:95.

Recebido em: 10/1/2007 Aprovado em: 29/3/2007 